\title{
WAR SIMULATIONS AND THE TEACHING OF MILITARY HISTORY
}

\author{
Steven Klein \\ Indiana University of Pennsylvania
}

During recent years, Departments of History, faced with the steady pressure of declining enrollments familiar to most in the profession, have resorted to a variety of ploys in order to attract college students back to historical studies. Such efforts have ranged from the sublime to the absurd, from new courses in family history or psychohistory to "The History of Pornography" or, better yet, "The History of the Pornographic Film." The efforts to broaden the appeal of history beyond the traditional modes of presentation of traditional topics has, of course, evoked a great deal of discussion and debate (not all of it polite). within the historical profession, much of it centering on the problems of intellectual and curricular integrity, as well as more formidable conundrums such as the nature and definition both of history and historical studies.

During the past several years the faculty at Indiana University of Pennsylvania has felt the ubiquitous and interrelated pressures of declining enrollments in history and the contemplated retrenchment of staff, and 1 t has reacted in the conventional manner, by broadening the content of its offerings and experimenting with innovative pedagogical techniques. The overall results have been very satisfactory, and, while some innovations have an ephemeral look, many others will no doubt remain an integral part of the department's future endeavors. One pedagogical device in particular proved to be especially successful. I am referring to the use of military simulations as pedagogical devices, not only for the teaching of military history per se, but also as a supplemental tool for the development of critical acuity in students and for the Improvement of thelr basic skills in research and analysis.

War-gaming, or the study and play of milltary simulations, has been steadily Increasing in popularity on college campuses during recent years, with a considerable number of students now enjoying the vicarious experiences of guiding Panzer Divisions, leading cavalry charges, or launching Banzai attacks. As both a student of military history and an avid war-gamer, it occurred to me that It might easily be possible to combine the two interests and introduce into the curriculum a course on military history which would incorporate into its format a generous use of the extensive number of the military simulations presently on the market. From that simple Idea evolved "Fighting the Great Wars."

Although the vartety of wilitary simulations is quite large and growing steadily, most of them have a common format. Each simulation usually consists of a map with salient features of terrain clearly defined and the surface of the map-sheet 1tself divided into contiguous hexagons. On the map square-cut counters representing military units of various types are placed and moved from hexagon to hexagon according to the rules of the game. In addition, each game is provided with a set of rules (occasionally unintelligible), a combat results table, and a die, which is used to resolve combat. Play of the game is usually sequential (although some games employ simultaneous movement), and both sides are usually faced with the problem of attaining certain mutually exclusive objectives within a specific length of time, perhaps ten game-turns, in order to determine the victor.

Although most games are built upon the basic system described above, the varlety of games and their scale is quite extensive. Some simulations deal with man-to-man combat while others are concerned with the movement of entire

An earlier version of this paper was presented at the Missouri Valley History Conference, Omaha, March 10, 1977. 
armies and fleets as well as the national productive capacities necessary to supply and maintain them. Some simulations are set in a city block in Stalingrad in 1942, while others have Europe or the world as their setting. Some games involve the movement of very few units; others require the movement of thousands of counters. The titles of a randomly selected set of games provide some idea of the variety: Drang Nach Osten, Sniper, Chariot, The Crimea, Hastings, France 1940, World War I, Midway, Cannae, and Trafalgar.

\begin{abstract}
"Fighting the Great Wars" had as its major themes the development of military tactics, strategy, organization, and technology from ancient times to World War II. The structure of the course was relatively simple, with blocks of lectures on general topics in military history presented in loose chronological order and interspersed with three two-week blocks reserved for the play of simulations. Due to a limited selection of available simulations, play was confined to tactics and strategy in the ancient world, the Napoleonic era, and the Second World War. Despite the rather simple format, the major problem was how to derive the maximum benefit from the use of simulations.
\end{abstract}

My solution was to combine written exercises with each game played or battle reenacted. For example, students were instructed to select two ancient battles, one from the Greek period and one from the Roman, which they were to simulate and about which they were to write an analytical essay. They were to study the ancient accounts of the battles or campaigns, as well as modern reconstructions, and then use their experiences during the simulations to analyze a number of problems of a purely military nature; for example, problems of terrain, the impact of weather, advantages of mobility, impact of supply, and the relative merits of various battle formations. The main purpose of the assignment was two-fold: to encourage an in-depth analysis of the original battles and their historical sources and to present students with the challenge of using their critical faculties to integrate their experiences during the simulations with their knowledge of historical events. If the reenactments deviated significantly from the historical events, they were encouraged to investigate the reasons for such deviations.

The results were quite gratifying and, to some extent, surprising. Most of the participants quickly began to do extensive research on the ancient battles, if for no other reason than to gain the advantage on their opponents. Their research naturally took them into a number of peripheral aspects of ancient warfare, such as the distance and accuracy of ancient archers or the size and speed of horses in the Roman cavalry. As the semester wore on, the students not only became quite adept at analyzing and increasing their understanding of past battles through the use of simulations, but they also became acute critics of faulty simulations and detectors of major factual errors by modern designers. (I eventually collected many of the criticisms and forwarded them to the manufacturers.)

The course ended with a marathon session devoted to the recreating of the Russo-German Campaign of 1941-45. At the time, there were two sections of "Fighting the Great Wars," so, naturally, one section commanded the forces of the Wehrmacht and the other those of the Red Army. Because of the great length of the simulation, play was to continue around the clock until a resolution, with groups of four students on a side particlpating for eight hours at a stretch. The beginning of the game was preceded by a media blitz on campus, which I orchestrated in order to arouse broader student interest: This final extravaganza (which lasted over fifty hours) was, in my judgement, a great success, and the enthusiasm of the two general staffs never wavered. Many of them brought: bedrolls to the site of the battle and stayed around the clock, and my wife was kind enough to provide abundant rations for both sides. (Upon purchasing five pounds of ham-spread, a salesclerk asked her if she intended to feed an army. 
She replied, "As a matter of fact, two armies!") Students, of course, were given a written assignment similar to the one mentioned above, based upon their experiences on the "Eastern Front."

It is important to note that "Fighting the Great Wars," despite certain successes, was not free from problems. For example, an instructor, thinking about integrating simulations into the structure of a course, must bear in mind that the simulations are competitive games with rules that can be quite complex. Not all students have a disposition toward such activity, while some students may simply not be sufficiently motivated to learn how to play adeptly. Consequently, I learned quickly that on the first day of class an instructor must clearly. explain the nature of military simulations and their role in the course, in order that students who have little interest in game simulations can react accordingly. Furthermore, an instructor must stress at the onset that rules must be studied and adherred to rigorously, and that students who are not prepared to expend sufficient effort in the course should not take it. This, in turn, leads to a second important consideration.

Students should be clearly advised that the play of simulations is merely a means to an end. An instructor may find that some students may show greater interest in "fun and games" than in serious work. I try to disabuse my students of such feelings by marking their early written work very severely and constantly reminding them that their main objective is to learn something, while hopefully having fun in the process. This approach seems to work reasonably well, and by the third week of class most students are balancing work and fun quite nicely.

A few logistical problems may also arise. Most simulations are two-player ones, and, therefore, a class of twenty students requires a sizeable number of tables and chairs. Obvious1y, a fairly generous supply of the games themselves is also necessary. In some cases, a number of students very kindly loaned me their own games when necessary, and the department was generous enough to purchase additional supplies. Finally, because of the length of play of certain games, a time period for the course in the late afternoon is probably optimal.

The above remarks describe my experlence with one course, "Fighting the Great Wars," and they are primarily intended to illustrate only one possible method of the employment of military simulations. In reality, the possible usages are considerable. For example, I will shortly be offering a course entitled "Warfare in Graeco-Roman Antiquity," which will employ military simulations. Why not a course entitled "Warfare in the Napoleonic Era" or "Military Leaders and Tactics of the American Civil War?" The variety of military simulations on the market is so vast that a remarkable number of courses is now possible. In addition, so-called "satellite" courses are becoming increasingly popular in the curriculum of some departments, and it would be very easy to design a satellite on some aspect of military history which would constitute an appendage of a core program such as Western Civilization. For students with an interest in military history who are taking a course offered in the traditional mold, there are numerous assignments and projects utilizing military simulations which could be designed to meet their interests, while still pursuing legitimate academic objectives.

In conclusion, there were at least two important consequences of my smali experience in "Fighting the Great Wars" which lead me to believe that military simulations can be an effective teaching supplement. First of all, the course attracted many students who would probably not have enrolled in a history course under normal circumstances, and I know for a fact that many of these students eventually enrolled in at least one more course in history. This was 
a very gratifying result to one who believes in the continued importance of the study of history, but not completely unexpected, since I firmly believe that once a student experiences something of the excitement of historical study he or she will frequently continue to cultivate that experience.

Secondly, assigmments which conjoined simulations and research assignments proved to be a different but successful method of introducing students to historical research and analysis. The majority of the students in the class demonstrated a great deal of enthusiasm in pursuing most of the assignments and by the end of the semester were writing detalled critical papers analyzing real and optimal levels of Soviet production during the Second World War, the relative merits of German and British armor, and Japanese tactics in the use of aircraft carriers, among other things.

In closing, the objective of this brief article has merely been to advise historians of the existence of a pedagogical device of which they may be unaware and to offer illustrations of its use. The methods of studying history are at least as varied as definitions of what history is. If one agrees that the study of history is a worthwhile, even necessary, endeavor, then it seems to me somewhat incumbent upon historians to convey that conviction and to justify it to as many college students as possible. Military simulations provide one more tool with which to perform that task. To be sure, military simulations are merely one means to an end, and their use can be abused. Moreover, different instructors will no doubt encounter different degrees of success with their employment. Nevertheless, in my judgment military simulations can be a very useful and stimulating device for bringing students to the study of history, albeit by somewhat unconventional means, and I am hopeful that others will be encouraged to experiment with them. 1

\section{NOTE}

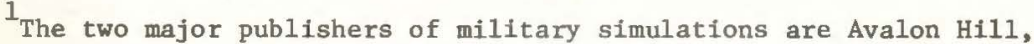
Baltimore, Maryland 21203 and Simulations Publications, Inc., 44 East 23rd Street, New York, New York 10010. S.P.I. publishes a magazine, Strategy and Tactics, which often provides descriptions of the publications of its rivals as well as their addresses. 